\title{
Coping with Stress in the Special Education Classroom Can Individual Teachers More Effectively Manage Stress?
}

\section{Mary Brownell}

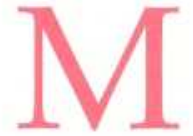

eeting the daily learning and behavioral needs of students makes teaching a stressful job. Although not all stress associated with teaching is negative, stress that reduces a teacher's motivation can have deleterious effects such as alienation from the workplace, absenteeism, and attrition. In fact, when special education teachers are highly stressed by the unmanageability of their workload, they are more likely to leave the special education classroom (Miller, Brownell, \& Smith, 1995). The ability to successfully manage stresses related to teaching is critical if special education teachers are to survive and thrive in the classroom.

\section{Coping in Bureaucracies}

Despite the current trend toward school-based decision making, many schools remain bureaucratic organizations where teachers have little control over major decisions in their environments and frequently work in isolation (Skrtic, 1991). Further, with increasing demands to be accountable, teachers' work is becoming more intense, leaving many teachers feeling emotionally exhausted (Hargreaves, 1994). Thus, in school bureaucracies, teachers may become stressed by role overload and lack of autonomy.
Additionally, since the focus of teachers' efforts is to help students, many teachers enter special education because of their desire to help children and youth. While the desire to help others can lead to strong student-teacher relationships and can provide teachers with commitment to education, this same desire can also make it difficult for teachers to leave their work at the schoolhouse door. In fact, professionals who are empathic, sympathetic, dedicated, idealistic, and people-oriented are vulnerable to experiencing excessive stress (Cherniss, 1980; Pines, Aronson \& Kafry, 1981), particularly when they face the multitude of problems that students with disabilities present.

Although special education teachers have many reasons to feel stressed, they can more effectively deal with stress by using specific strategies. As such, the following suggestions are provided to help teachers manage their stress levels.

\section{Set Realistic Expectations}

As a teacher, you can alleviate some of the stress caused by role overload by setting realistic expectations for yourself (Greer \& Greer, 1992; Shaw, Bensky, \& Dixon, 1981 as cited in ERIC Digest, 1989). As part of their preservice education, special education teachers are taught to identify the individual needs of students and develop individualized programs for these students. Thus, teachers may develop the expectation that being a successful teacher translates into the ability to solve all students' problems (Greer \& Greer, 1992). Although this expectation is commendable, it is not always possible, particularly for beginning teachers. To competently manage the challenging, diverse needs of students with disabilities, professionals need to perform at a high level in the areas of curriculum, behavior management, instructional management, collaboration, and paperwork completion. Attempting perfection in each of these areas, especially early in your career, may be unrealistic. Instead, consider targeting one area for improvement over the course of a year and learn as much as you can either through reading, completing course work, or sharing with colleagues. You can also develop more realistic expectations of what you can accomplish. It is impossible to complete all aspects of an overwhelming job with perfection, so setting priorities is a must. List the jobs you must accomplish on a daily basis and determine those that are a priority to you personally and to your administration, and deal with those jobs in order of importance.

Also, develop more realistic expectations about what you can accomplish with students. Reduce the scope and intensity of the emotional relationship you have with students by learning to see them in a more objective light. When working with students with disabilities, teachers can find themselves frustrated by the slow progress students make in learning and in managing their own behavior. In this case, teachers need to remind themselves of the severity of their stu- 


\section{3:3 Fall 2006}

dents' challenges and realize that lack of student progress does not necessarily indicate shortcomings on the teacher's part. Also, realize that although you care for your students, you can only accomplish so much in a school day. If you are working hard each day for your students, pat yourself on the back and recognize that you cannot do it all.

\section{Make Distinctions Between Your Job and Your Personal Life}

Today, a host of sociological factors, such as poverty, child abuse, and single parent families, affect many school-age children. Consequently, teachers are faced with educating students who present a complex array of problems. Being able to show empathy for students and their problems without allowing those problems to consume you is critical.

"Teachers who become closely involved and preoccupied with the personal and family problems of their students may increase their vulnerability to burnout" (Greer \& Greer, 1992, p. 170).

When you leave the classroom, do the mental work necessary to leave thoughts of your students in the work environment. If you need to share feelings or vent frustrations, set aside a time once or twice a week to discuss them with another teacher, friend, or significant other. When you discuss frustrations, try to find solutions to the stressful situation. Repeated discussion about your frustrations without any solution only heightens them.

\section{Find Ways to Exercise} Professional Discretion and Increase Your Autonomy

In bureaucracies, authority is "commonly expressed in rules, job descriptions, and work schedules" (Pines \& Aronson, 1988, p. 109). Often the environment seems inflexible at first glance, but in reality the rules are frequently general and open to interpretation. Thus, evaluate each aspect of your job and determine changes to improve your environment that you can reasonably make. Focus your energy on those changes, and leave behind changes that are not within your control. Focusing on "the possible" increases your sense of power and control.

\section{Don't Expect Praise from the Boss}

Relying on the principal or district special education director to provide recognition for your hard work is most likely unrealistic. Look for alternative sources of reinforcement, such as students, colleagues, friends, or parents. Also, increase the probability of obtaining reinforcement by informing supervisors and parents of your successes. For example, keep records of student progress that you can share with others.

\section{Increase Your Efficacy}

Teachers who have a heightened sense of efficacy, that is, confidence in their ability to teach and manage students, may be less vulnerable to stress because they perceive themselves as having the tools to do their jobs (Bandura, 1993). By keeping records of student progress, you can receive direct feedback on your efforts (Greer \& Greer, 1992). Being able to observe student progress is essential, as it is likely to increase your sense of efficacy (Guskey, 1985) and thus reduce the stress you experience. Additionally, implementing best practices in your classroom can increase your sense of efficacy. When you implement best practices and see the resulting student progress, your sense of efficacy typically increases (Englert \& Tarrant, 1995; Guskey, 1985).

\section{Develop Personal Coping Strategies}

Teachers would be well-advised to develop strategies to cope with stress in their teaching positions and personal lives. Research on stress suggests that people have two basic approaches to coping with stress: active and inactive coping strategies. People who use active coping strategies are attempting to change the source of stress or themselves. In contrast, persons who use inactive coping strategies avoid or deny the source of stress. Active coping strategies are considerably more effective in managing stress.

\section{Direct active strategies}

When teachers use direct active coping strategies, they directly intervene with the source of the stress in a way that minimizes the stressful situation. Pines and Aronson (1988) have identified three direct active strategies that employees can use to more effectively manage stress.

First, you can change the source of your stress. You can reduce stress by changing the nature of the stressful situation. For instance, if you perceive that general education teachers in your building are not supportive of your efforts to include students, you may be able to work with your building principal and 
a general education teacher who is an ally to provide staff development sessions focusing on effective instruction or behavior management for students with disabilities and high-risk students. These staff development sessions could be conducted at faculty meetings or during teacher workdays. By selecting adaptations that are concrete and easy to implement, providing opportunities for ongoing dialogue about the implementation, and supporting teachers in their efforts to learn selected techniques, you can begin to change the practices of your general education colleagues (Gersten \& Woodward, 1990). Once your colleagues can see change in students with disabilities, they should be more confident in their ability to teach students with disabilities and more willing to teach these students (Guskey, 1985).

Second, you can confront the source of your stress. You can directly deal with stress by discussing problems you are having with a colleague or student. For instance, you may find that you are encountering difficulties working with your paraprofessional. To work through these difficulties, you can suggest to your paraprofessional that there appear to be some notable tensions when you work together. By airing these difficulties and attempting to negotiate a solution, you may be able to resolve your problems.

Third, you can adopt a positive attitude. When you focus on the positive aspects of your work situation, you can change how you perceive stress and cope with stressful events more effectively (Pines \& Aronson, 1988). Try keeping a cheerful, upbeat attitude and remind yourself continually about the aspects of your job that you enjoy. Also, focus on giving others in your environment positive feedback. When you exhibit a positive outlook, others may seek your company, and in turn, you might receive the recognition and support you need.

\section{Indirect active strategies}

When teachers use indirect active coping strategies, they attempt to reduce their stress by releasing it or engaging in activities known to reduce stress. They do not, however, attempt to change the source of the stress. The following are a list of indirect active strategies that have been cited in the literature as effective (Greer \& Greer, 1992; Pines \& Aronson, 1988).

First, you can talk about the source of your stress. As mentioned earlier, seeking the support of others to discuss your stress may be helpful. Talking stressful situations over with a trusted colleague or friend may help you to resolve problems you are encountering. Often, people find that after discussing issues that are disturbing them they are less stressed, particularly when they can generate solutions for the stressful situation. Carefully select the person with whom you want to share your troubles. A person who can keep confidences and help you see the situation more objectively is often the best source of support.

Second, you can change the way you perceive the source of your stress. When people change the way they view the stress, they are taking steps toward reducing their stress. As mentioned earlier, developing more realistic expectations about your students goes a long way toward relieving guilt, worry, and subsequent stress. Also, examine the personality and strengths of other professionals in your environment. Determining what you can realistically expect from these professionals will assist you in identifying those persons from whom you can solicit support.

Third, you can get involved in other activities that take your mind off school issues. Finding hobbies, exercising, and seeking social outlets outside of school will help you to mentally distance yourself from work. Exercising is documented to be particularly effective in reducing stress (Long, 1988) and the physical symptoms associated with stress. Also, having time for yourself, whether you are exercising or engaging in another enjoyable activity, is paramount to gathering your thoughts and rejuvenating yourself.

Often, people find that after discussing issues that are disturbing them they are less stressed, particularly when they can generate solutions for the stressful situation. Carefully select the person with whom you want to share your troubles. A person who can keep confidences and help you see the situation more objectively is often the best source of support.

Finally, you can change your diet to reduce stress. Certain foods, such as coffee, chocolate, and soft drinks, are loaded with 


\section{3:3 Fall 2006}

caffeine, a stimulant known to increase anxiety. If you are experiencing extreme stress, try cutting caffeine products out of your diet. Also, teachers' diets often overemphasize refined carbohydrates and fatty foods with an inadequate emphasis on fiber (Bradfield \& Fones, 1984). Decreasing your fat, sugar, and caffeine intake while increasing your intake of fruits and vegetables may help you feel better physically and mentally.

Researchers have established that effective coping strategies reduce workplace related stress. District and school administrators, however, are ultimately responsible for reducing stress in the school environment (see Aronson \& Pines, 1988). Expecting teachers to better manage their stress in an unsupportive environment where clear role expectations do not exist is an unproductive approach to resolving teacher burnout problems. Efforts to create more productive, caring, clearly defined work situations and improve teachers' skills are the best prevention against teacher stress.

\section{References}

Bandura, A. (1993). Perceived self-efficacy in cognitive development and functioning. Educational Psychologist, 28, 117-148.

Bradfield, R., \& Fones, D. (1984). Recipe for burnout: The special education teachers' diet. Academic Therapy, 19, 499-504. ERIC Document Reproduction Service No. EJ298251).

Brownell, M., Smith, S., \& Miller, M. (May, 1995). Retention and attrition in special education: Analysis of variables that predict staying, transferring, or leaving. Paper prepared for the National Dissemination Forum on Issues Related to Special Education Teacher Satisfaction, Retention and Attrition, Washington, D. C. (ERIC Document Reproduction Service No. ED389157).

Cherniss, C. (1980). Professional Burnout in Human Service Organizations. New York: Praeger.

Englert, C. S., \& Tarrant, K. L. (1995). Creating collaborative cultures for educational change. Remedial and Special Education, 16, 325-336. (ERIC Document Reproduction Service No. EJ513554).

ERIC Digest. (1989). Fourteen Tips to Help Special Educators Deal with Stress. Reston, VA: The ERIC Clearinghouse on Handicapped and Gifted Children, The Council for Exceptional Children.

Gersten, R. \& Woodward, J. (1990), Rethinking the regular education initiative: Focus on the classroom teacher. Remedial and Special Education, 11, 7-16. (ERIC Document Reproduction Service No. EJ414956).

Greer, H. G., \& Greer, B. B. (1992). Stopping burnout before it starts: Prevention measures at the preservice level. Teacher Education and Special Education, 15(3), 168-174. (ERIC Document Reproduction Service No. EJ455745).

Guskey, T. R. (1985). The effects of staff development on teachers' perceptions about effective teaching. Journal of Educational Research, 78, 378-381. (ERIC Document Reproduction Service No. EJ321723).

Hargreaves, A. (1994). Changing Teachers, Changing Times: Teacher's Work and Culture in the Postmodern Age. New York: Teachers College Press.

Long, B. (1988). Stress management for school personnel: Stress-inoculation training and exercise. Psychology in the Schools, 25, 314-324. (ERIC Document Reproduction Service No. EJ379691).

Pines, A. \& Aronson, E. (1988). Career Burnout: Causes and Cures. New York: Free Press.

Pines, A., Aronson, E. \& Kafry, D. (1981). Burnout: from Tedium to Personal Growth. New York Free Press.
Skrtic, T. M. (1991). Behind Special Education: a Critical Analysis of Professional Culture and School Organization. Denver: Love Publishing.

Mary Brownell personally provided permission to reprint this paper according to a modified format suitable for publication in Teaching and Learning. This publication was prepared with funding from the Office of Educational Research and Improvement, U.S. Department of Education, under contract no. RR93002005. The opinions expressed in this report do not necessarily reflect the positions or policies of OERI or the Department of Education. ERIC EC Digest \#E545

Author: Mary Brownell June 1997 ericec@cec.sped.org Internet: http:// ericec.org
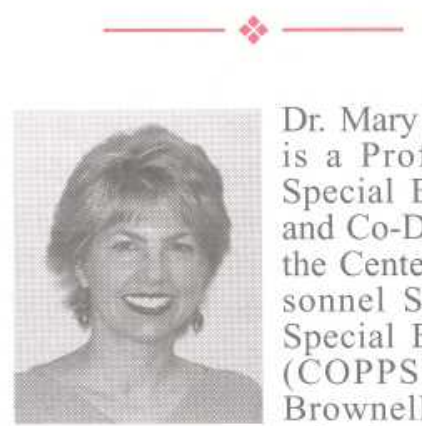

Dr. Mary Brownell is a Professor of Special Education and Co-Director of the Center for Personnel Studies in Special Education (COPPSE). Dr. Brownell is committed to the preparation and on going career development of well qualified special education teachers. Her interests include quality of work issues, decisions to remain in or leave the classroom; the role of collaboration and socialization and life long career development. To support her work, Dr. Brownell, in collaboration with colleagues from the University of Florida and other institutions, has secured 7 federal grants totaling more than 12 million dollars from the U.S. Department of Education, Office of Special Education Programs and Institute for Education Sciences. Her work has also been translated into numerous scholarly publications and presentations that reach the teacher education, research, policy, and school communities. She received the 1999 UF Research Foundation Professorship in the College of Education; two national awards for journal publications and two College of Education Teaching Awards. 